\title{
Long-acting inhaled anticholinergic therapy improves sleeping oxygen saturation in COPD
}

\author{
W.T. McNicholas*, P.M.A. Calverley" ${ }^{\#}$ A. Lee ${ }^{\Uparrow}$, J.C. Edwards ${ }^{+}$, on behalf of the Tiotropium Sleep Study \\ in COPD Investigators
}

Long-acting inhaled anticholinergic therapy improves sleeping oxygen saturation in COPD. W.T. McNicholas, P.M.A. Calverley, A. Lee, J.C. Edwards, on behalf of the Tiotropium Sleep Study in COPD Investigators. (C) ERS Journals Ltd 2004.

ABSTRACT: Oxygen desaturation occurs during sleep in severe chronic obstructive pulmonary disease (COPD), especially during rapid eye movement (REM) sleep, due to hypoventilation and ventilation-perfusion mismatching, but the possible contribution of airflow limitation is unclear.

In a randomised, placebo-controlled, double-blind study of severe, stable COPD patients, the authors compared 4 weeks treatment with a long-acting inhaled anticholinergic agent (tiotropium), taken in the morning (tiotropium-AM), or in the evening (tiotropium-PM), on sleeping arterial oxygen saturation $\left(\mathrm{S}_{\mathrm{a}}, \mathrm{O}_{2}\right)$ and sleep quality. Overnight polysomnography was performed at baseline and after 4 weeks treatment. A total of 95 patients with awake resting arterial oxygen tension $\leqslant 9.98 \mathrm{kPa}(75 \mathrm{mmHg})$ were randomised, with a mean age of $66.4 \mathrm{yrs}$ and mean forced expiratory volume in one second (FEV1) of 32\% predicted.

A total of 80 patients completed the study, of which 56 fulfilled the polysomnographic criterion of at least $2 \mathrm{~h}$ sleep in both sleep study nights and represent the group analysed. Tiotropium significantly improved spirometry compared with placebo. Both tiotropium-AM and tiotropium-PM groups had higher $S_{\mathrm{a}}, \mathrm{O}_{2}$ during REM than placebo $(+2.41 \%$ and $+2.42 \%$, respectively, and both pooled and tiotropium-PM groups had higher $\mathrm{S}_{\mathrm{a}, \mathrm{O}_{2}}$ during total sleep time $(+2.49 \%$ and $+3.06 \%$, respectively). End-oftreatment FEV1 correlated with $S_{\mathrm{a}}, \mathrm{O}_{2}$ during REM sleep, however, tiotropium did not change sleep quality.

Sustained anticholinergic blockade improves sleeping arterial oxygen saturation without affecting sleep quality.

Eur Respir J 2004; 23: 825-831.
*St. Vincent's University Hospital, Elm Park, and ${ }^{+}$Boehringer Ingelheim Ireland Ltd, Dublin, Ireland. "University Hospital Aintree, Liverpool, and "Boehringer Ingelheim Ltd, Bracknell, UK.

Correspondence: W.T. McNicholas

Dept of Respiratory Medicine

St. Vincent's University Hospital

Elm Park

Dublin 4

Ireland

Fax: 35312697949

E-mail: walter.mcnicholas@ucd.ie

Keywords: Chronic obstructive pulmonary disease

randomised controlled trial

sleep-disordered breathing

tiotropium bromide

Received: July 242003

Accepted after revision: March 152004

This study was entirely supported by a grant from Boehringer Ingelheim Ltd.
Sleep can be associated with clinically important adverse effects in patients with chronic obstructive pulmonary disease (COPD), principally disordered gas exchange and disturbances in sleep quality [1]. Sleep-related hypoxaemia and hypercapnia are well recognised in such patients, particularly during rapid eye movement (REM) sleep, and may contribute to cardiac arrhythmias during sleep [2] and predispose to nocturnal death during exacerbations [3]. The principal mechanism of disordered gas exchange during sleep is the physiological hypoventilation that is a normal feature of sleep, which has a disproportionate effect in hypoxaemic patients because of their position on the oxyhaemoglobin dissociation curve [4]. In addition, the physiological reduction in accessory muscle contribution to breathing, particularly during REM sleep, results in a decreased functional residual capacity, which leads to worsening ventilation-to-perfusion relationships, and further aggravates hypoxaemia [5]. Whether the severity of airflow limitation directly contributes to the degree of hypoventilation and/or oxygen desaturation is unclear, but cholinergic mechanisms could play a role in increasing airflow obstruction, since cholinergic tone has a normal circadian rhythm with higher levels during the sleeping hours [6].

Hypoxaemia during sleep is easily corrected by supplementary oxygen [7, 8], although whether this improves sleep quality is less clear [7-10]. An alternative approach would be to ameliorate some of the factors contributing to hypoxaemia during sleep described above, and a previous study of ipratropium, a short-acting anticholinergic bronchodilator, has shown improvement in sleep arterial oxygen saturation in COPD patients [11].

Tiotropium is a new anticholinergic bronchodilator with duration of action in excess of $24 \mathrm{~h}$ due to prolonged M3-receptor occupancy, thus allowing once-daily dosing. This has been confirmed in single-dose studies and over 3 months-1 yr of regular therapy [12-14]. It is not known if tiotropium can improve nocturnal oxygenation while maintaining or improving sleep quality. The current authors conducted a prospective, randomised, double-blind, placebocontrolled study of parallel-group design, to assess the effect of tiotropium on nocturnal sleeping arterial oxygen saturation $\left(\mathrm{Sa}, \mathrm{O}_{2}\right)$ and sleep quality, and to establish whether the time of dosing (morning or evening) was relevant to these sleep-related effects. The primary study end-point was the absolute value of the average $\mathrm{Sa}, \mathrm{O}_{2}$ during REM sleep at the end of the treatment period and the comparison of interest was that between morning (AM) or evening (PM) tiotropium and placebo.

\section{Methods}

\section{Patient selection}

Patients $>40$ yrs with a diagnosis of COPD by standard criteria [15] were considered for recruitment. They were 
required to be current or exsmokers with a smoking history $\geqslant 10$ pack-yrs, to have a forced expiratory volume in one second (FEV1) $\leqslant 65 \%$ predicted [16] and a FEV1/forced vital capacity (FVC) ratio $\leqslant 70 \%$, in addition to an awake arterial oxygen tension $\left(\mathrm{Pa}, \mathrm{O}_{2}\right) \leqslant 9.98 \mathrm{kPa}(75 \mathrm{mmHg})$ prior to entry. Patients were excluded if they were receiving regular oxygen therapy, had a clinically significant recent or concomitant disease other than COPD, or evidence of sleep apnoea on baseline sleep studies ( $\geqslant 10$ apnoeas or hypopnoeas per hour of sleep). Additional exclusion criteria included: evidence of asthma or atopy; respiratory infection in the preceding 6 weeks; symptomatic urinary outflow obstruction; narrow-angle glaucoma; or hypersensitivity to any of the test ingredients. Other permitted medications during the study were inhaled corticosteroids $\leqslant 1,500 \mu \mathrm{g}$ daily, oral corticosteroids $\leqslant 10 \mathrm{mg}$ daily of prednisolone (or equivalent) and inhaled salbutamol taken as required.

\section{Design and methods}

Patients were randomised at 12 sites in three countries. The ethics committee of each site approved the trial and all patients gave written informed consent. A flow-chart of study assessments is given in figure 1. Each subject spent 3 nights in the sleep laboratory: the acclimatisation night; the baseline night (before randomisation); and the end-of-study night (4 weeks after randomisation). During the acclimatisation study all electrodes and probes normally used in polysomnography were attached but not recorded. The baseline and end-of-treatment sleep studies were performed overnight using standard polysomnographic techniques [17, 18]. Epworth sleepiness scores [19, 20] were recorded before sleep, and spirometry was measured before and after sleep. The Epworth score is a widely accepted subjective evaluation of sleepiness that is commonly used in the evaluation of sleepiness in patients with sleep-related breathing disorders. Patients were randomised to trial treatment the following morning. The randomisation of trial treatment was stratified into two groups (low $\mathrm{Pa}, \mathrm{O}_{2}: \leqslant 8.65 \mathrm{kPa}(65 \mathrm{mmHg}$ ); high

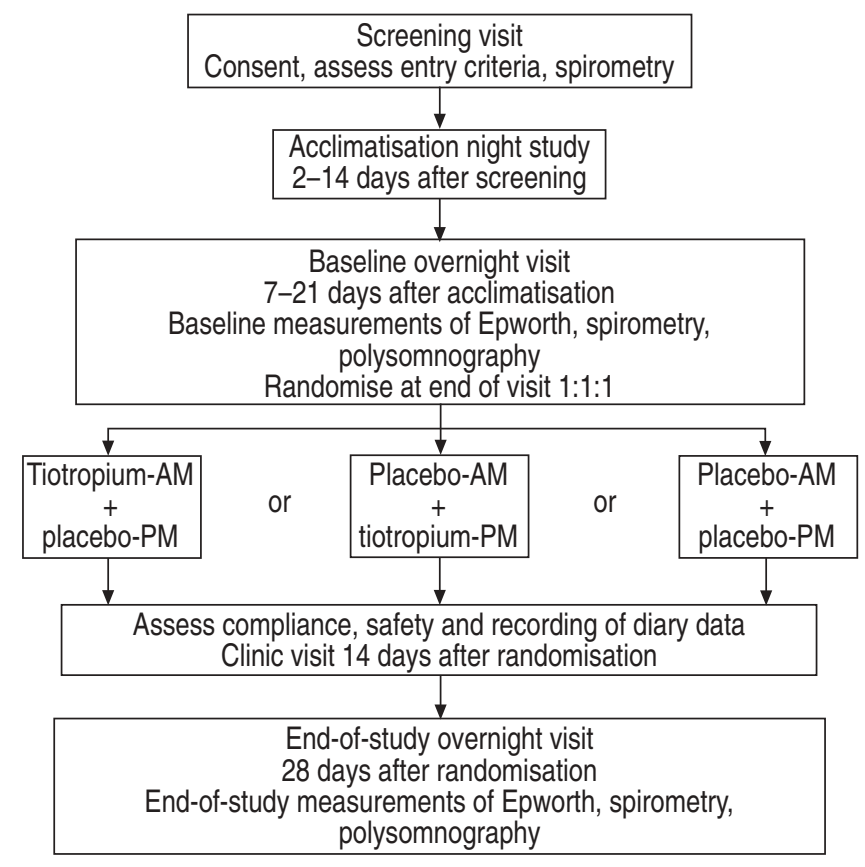

Fig. 1. - A flow chart of study assessments.
$\left.P a, \mathrm{O}_{2}: 8.78-9.98 \mathrm{kPa}(66-75 \mathrm{mmHg})\right)$ according to the awake $\mathrm{Pa}, \mathrm{O}_{2}$ at screening, and patients took the first dose under supervision.

Polysomnographic data from all centres were assessed by an independent centre, which did not recruit any patients and was blind to the identity of the trial treatments. Patients were given trial treatments for 28 days and were randomised to one of the following groups in a 1:1:1 ratio: 1) tiotropium AM and placebo PM; b) placebo AM and tiotropium PM; or c) placebo AM and PM. Tiotropium $(18 \mu \mathrm{g})$ was given mixed with lactose in a capsule via a dry powder inhalation device (HandiHaler $\mathbb{R}$; Boehringer Ingelheim, Ingelheim-am-Rhein, Germany). During the final overnight assessment all baseline measurements were repeated.

During the trial period of 4 weeks, patients recorded a daily diary of their morning and evening peak expiratory flow rate, daytime alertness, perception of sleep quality, respiratory symptoms, number of puffs of rescue salbutamol and compliance with trial medication. Electrocardiograms, haematology and serum chemistry were assessed at screening and at the end of study. All adverse events were recorded.

\section{Statistical analysis}

The primary statistical model for all continuous end-points was analysis of covariance (ANCOVA) with terms for treatment and baseline $\mathrm{Pa}, \mathrm{O}_{2}$, with end-point baseline used as a linear covariate. ANCOVA adjusts outcome values for baseline differences, thus providing information about any differential treatment effect [21, 22]. A secondary model, including the interaction term between treatment and baseline, was also fitted to investigate the consistency of treatment response across baseline values. The Mann-Whitney test was used to compare the time spent in the various sleep stages (I, II, III/IV and REM) as a percentage of the total sleep time (sum of stage I, II, III/IV and REM durations). For the primary comparison between tiotropium and placebo, all tiotropium-treated patients were pooled as one group. All patients who had at least $2 \mathrm{~h}$ total sleep during both baseline and post-treatment clinic sleep nights, and had adequate baseline and post-treatment data, were included in the efficacy analyses. This requirement was established in advance of analysis on the basis that the ANCOVA requires measurements from both baseline and post-treatment sleep studies and a $2 \mathrm{~h}$ duration was thought likely to include some REM sleep. However, not all of these patients could be included in $\mathrm{Sa}, \mathrm{O}_{2}$ analysis since six patients failed to achieve REM sleep in either baseline or post-treatment studies and a further three patients had technical problems with $\mathrm{Sa}, \mathrm{O}_{2}$ recordings in one or other sleep study. Thus, efficacy analysis for $\mathrm{Sa}_{\mathrm{a}} \mathrm{O}_{2}$ in REM sleep was based on 47 patients and for total sleep time on 52 patients. All tests were two-sided carried out at the $5 \%$ significance level. Unless otherwise stated, statistics are given as least squares mean \pm SE. Least squares means are estimates of the means that would have been expected had the design been balanced with all the covariates at their mean value $[21,22]$.

\section{Results}

The disposition of patients is shown in figure 2. A total of 95 patients with COPD were randomised and 80 patients completed the 4-week treatment trial. A total of 56 patients fulfilled the $a$ priori criteria of at least $2 \mathrm{~h}$ of documented sleep on polysomnography at both baseline and final visits, and this group forms the basis of the primary analysis of nocturnal 


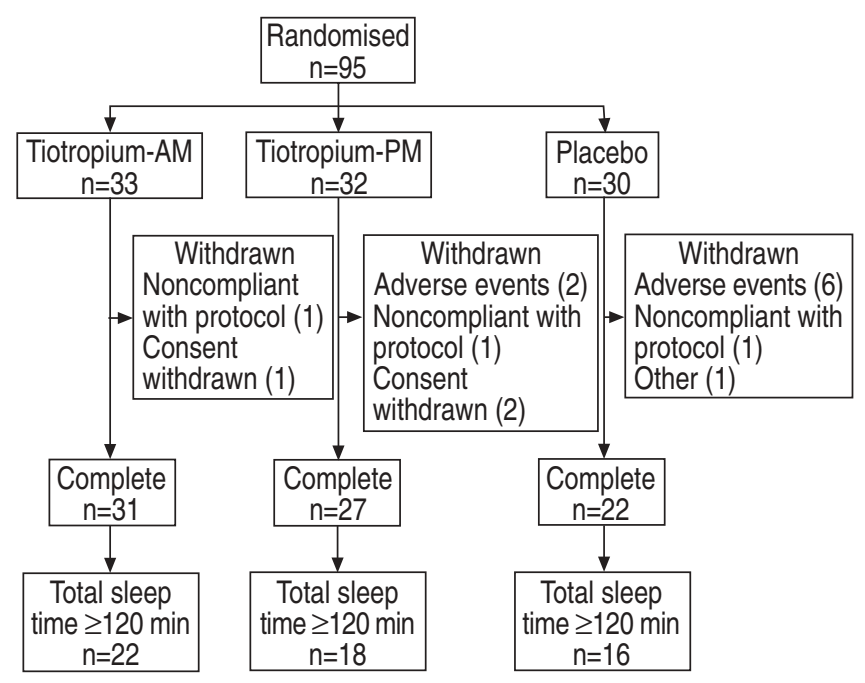

Fig. 2. - The disposition of patients in the study.

$\mathrm{Sa}, \mathrm{O}_{2}$ and sleep quality. Patients' characteristics at baseline of the 95 randomised patients were similar between the treatment groups, and most patients had severe disease with an average FEV1 of $32 \%$ pred (table 1), and the baseline characteristics of the 56 evaluated patients were no different. The mean $\mathrm{Pa}, \mathrm{O}_{2}$ in the randomised patients at screening was $8.59 \mathrm{kPa}(64.6 \mathrm{mmHg})$ and was similar across the three treatment groups. Randomisation of the trial treatment was evenly split between the high and low $\mathrm{Pa}, \mathrm{O}_{2}$ strata of greater or less than $8.65 \mathrm{kPa}(65 \mathrm{mmHg})$ with 49 patients $(52 \%)$ randomised in the higher stratum and 46 patients $(48 \%)$ in the lower stratum.

\section{Oxygen saturation}

The principal comparators were the absolute values of $\mathrm{Sa}, \mathrm{O}_{2}$ during REM sleep at the beginning and at the end of the study. There were no differences in awake $\mathrm{Sa}, \mathrm{O}_{2}$ between tiotropium-AM or -PM with placebo, either at baseline (mean \pm SE: $90.8 \pm 0.81 ; 89.9 \pm 0.93$; and $89.4 \pm 0.99$, respectively) or at the end of treatment $(90.7 \pm 0.81 ; 91.4 \pm 0.96$; and $89.6 \pm 0.99$; with $\mathrm{p}$-values for all comparisons $\geqslant 0.27$ ). Data showing $\mathrm{Sa}, \mathrm{O}_{2}$ levels during sleep with tiotropium and placebo are given in tables 2 and 3 . After 4 weeks of treatment with tiotropium, mean $\mathrm{Sa}, \mathrm{O}_{2}$ during REM sleep (adjusted for baseline differences) was significantly higher than placebo (table 2) and the average difference for both tiotropium groups pooled compared with placebo was $2.4 \%(\mathrm{p}=0.008)$. The duration of REM sleep was similar in all treatment groups (table 4). The higher level of $\mathrm{Sa}, \mathrm{O}_{2}$ during REM sleep in the tiotropium group was significant irrespective of the $\mathrm{Pa}_{\mathrm{O}} \mathrm{O}_{2}$ stratum at baseline. There was no difference in the effects on $\mathrm{Sa}, \mathrm{O}_{2}$ during REM sleep between tiotropium given in the morning as opposed to the evening.

Data for the comparison of $\mathrm{Sa}, \mathrm{O}_{2}$ during total sleep time between tiotropium and placebo are given in table 3. After adjustment for baseline differences, $\mathrm{Sa}, \mathrm{O}_{2}$ was significantly higher than placebo in the pooled tiotropium group and among those receiving tiotropium in the evening $(\mathrm{p}<0.05$ for

Table 1.-Demographics and baseline characteristics

\begin{tabular}{|c|c|c|c|c|}
\hline Characteristic & Tiotropium-AM & Tiotropium-PM & Placebo & Total \\
\hline Total treated & 33 & 32 & 30 & 95 \\
\hline Male sex n $(\%)$ & $22(67)$ & $21(66)$ & $23(77)$ & $66(70)$ \\
\hline Age yrs & $66.7(48-77)$ & $65.1(54-79)$ & $67.6(49-82)$ & $66.4(48-82)$ \\
\hline Weight $\mathrm{kg}$ & $70.6(46-113)$ & $72.8(40-100)$ & $70.5(44-109)$ & $71.3(40-113)$ \\
\hline Height $\mathrm{cm}$ & $166.8(134-182)$ & $168.1(140-192)$ & $169.2(152-188)$ & $168.0(134-192)$ \\
\hline \multicolumn{5}{|l|}{ Smoking history } \\
\hline Current smoker n $(\%)$ & $12(36)$ & $9(28)$ & $9(30)$ & $30(32)$ \\
\hline Pack-yrs & $50.4(10-186)$ & $46.5(12-120)$ & $51.6(10-130)$ & $49.5(10-186)$ \\
\hline FEV1 L & $0.82 \pm 0.27$ & $0.87 \pm 0.32$ & $0.81 \pm 0.31$ & $0.84 \pm 0.30$ \\
\hline FVC L & $1.89 \pm 0.62$ & $2.01 \pm 0.80$ & $1.95 \pm 0.62$ & $1.95 \pm 0.68$ \\
\hline FEV $1 / \mathrm{FVC} \%$ & $45 \pm 10$ & $46 \pm 14$ & $43 \pm 13$ & $44 \pm 12$ \\
\hline FEV1 \% predicted & $33 \pm 12$ & $33 \pm 13$ & $31 \pm 12$ & $32 \pm 12$ \\
\hline $\mathrm{Pa}, \mathrm{O}_{2} \mathrm{mmHg}$ & $66.0 \pm 6.9$ & $64.1 \pm 6.8$ & $63.5 \pm 7.8$ & $64.6 \pm 7.2$ \\
\hline Low $\mathrm{Pa}, \mathrm{O}_{2}$ stratum $\leqslant 65 \mathrm{mmHg}$ n $(\%)$ & $13(39.4)$ & $18(56.3)$ & $15(50.0)$ & $46(48.4)$ \\
\hline High $\mathrm{Pa}, \mathrm{O}_{2}$ stratum $66-75 \mathrm{mmHg}$ n $(\%)$ & $20(60.6)$ & $14(43.8)$ & $15(50.0)$ & $49(51.6)$ \\
\hline
\end{tabular}

Data are presented as mean (range) or mean \pm SD unless otherwise stated. FEV1: forced expiratory volume in one second; FVC: forced vital capacity; $P a, \mathrm{O}_{2}$ : awake arterial oxygen tension. Total randomised patients: $\mathrm{n}=95$. All patients were Caucasian. $1 \mathrm{mmHg}=0.133 \mathrm{kPa}$.

Table 2.-Oxygen saturation (\%) during rapid eye movement (REM) sleep and differences between treatment groups at end of study

\begin{tabular}{|c|c|c|c|c|c|c|c|}
\hline Comparison & Tiotropium-AM & Tiotropium-PM & $\begin{array}{l}\text { Tiotropium } \\
\text { pooled }\end{array}$ & Placebo & $\begin{array}{l}\text { Difference } \\
\text { in } \% \text { points }\end{array}$ & p-value & $95 \% \mathrm{CI}$ \\
\hline Subjects $n$ & 19 & 17 & 36 & 11 & & & \\
\hline Tiotropium-AM versus placebo & $89.97(0.59)$ & & & $87.56(0.76)$ & 2.41 & 0.016 & $0.48-4.33$ \\
\hline Tiotropium-PM versus placebo & & $89.98(0.62)$ & & 87.56 & 2.42 & 0.020 & $0.41-4.43$ \\
\hline Tiotropium pooled versus placebo & & & $89.98(0.41)$ & 87.56 & 2.41 & 0.008 & $0.68-4.15$ \\
\hline
\end{tabular}

Data are presented as mean (SE) unless otherwise stated and are from the patient population with total sleep time of at least $2 \mathrm{~h}$. Some patients did not have any REM sleep at baseline or end of study. Means are adjusted for baseline arterial oxygen saturation $\left(\mathrm{Sa}_{2} \mathrm{O}_{2}\right)$ and arterial oxygen tension. Overall mean baseline $\mathrm{Sa}, \mathrm{O}_{2}$ during REM sleep=88.74\%. 
Table 3.-Oxygen saturation (\%) during total sleep time and differences between treatment groups at end of study

\begin{tabular}{|c|c|c|c|c|c|c|c|}
\hline Comparison & Tiotropium-AM & Tiotropium-PM & $\begin{array}{c}\text { Tiotropium } \\
\text { pooled }\end{array}$ & Placebo & $\begin{array}{l}\text { Difference } \\
\text { in } \% \text { points }\end{array}$ & $\mathrm{p}$-value & $95 \% \mathrm{CI}$ \\
\hline Subjects $n$ & 21 & 18 & 39 & 13 & & & \\
\hline Tiotropium-AM versus placebo & $89.83(0.84)$ & & & $87.82(1.05)$ & 2.01 & 0.141 & $-0.69-4.71$ \\
\hline Tiotropium-PM versus placebo & & $90.88(0.92)$ & & 87.82 & 3.06 & 0.035 & $0.23-5.91$ \\
\hline Tiotropium pooled versus placebo & & & $90.31(0.61)$ & 87.82 & 2.49 & 0.047 & $0.02-4.93$ \\
\hline
\end{tabular}

Data are presented as mean (SE) unless otherwise stated and are from the patient population with total sleep time of at least $2 \mathrm{~h}$. Means are adjusted for baseline arterial oxygen saturation $\left(\mathrm{Sa}_{\mathrm{a}} \mathrm{O}_{2}\right)$ and arterial oxygen tension. Overall mean baseline $\mathrm{Sa}, \mathrm{O}_{2}$ during total sleep time=89.58\%.

Table 4. - Effect of tiotropium (pooled AM and PM) versus placebo on duration of sleep stages, latency to persistent sleep and latency to rapid eye movement (REM) sleep

\begin{tabular}{|c|c|c|c|c|c|}
\hline Stage & Overall mean baseline & Tiotropium & Placebo & Difference & p-value \\
\hline Subjects $n$ & & 40 & 16 & & \\
\hline Awake & 120.3 & $110.0(9.8)$ & $120.3(15.7)$ & -10.3 & 0.585 \\
\hline Stage I & 40.5 & $39.4(4.9)$ & $50.8(7.7)$ & -11.4 & 0.219 \\
\hline Stage II & 158.8 & $168.1(10.1)$ & $147.0(16.1)$ & 21.1 & 0.275 \\
\hline Stage III/IV & 40.4 & $35.2(4.6)$ & $47.9(7.3)$ & -12.7 & 0.146 \\
\hline REM & 37.8 & $52.1(4.6)$ & $51.1(7.4)$ & 1.0 & 0.906 \\
\hline Total sleep time & 277.4 & $294.4(11.1)$ & $297.8(17.6)$ & -3.4 & 0.871 \\
\hline Total sleep period & 397.7 & $408.7(12.0)$ & $408.2(19.2)$ & 0.5 & 0.982 \\
\hline Latency to persistent sleep & 30.8 & $\begin{array}{l}32.2(5.3) \\
36\end{array}$ & $40.9(8.0)$ & -8.7 & 0.370 \\
\hline $\begin{array}{l}\text { Subjects } n \\
\text { Latency to REM sleep }\end{array}$ & 120.4 & $\begin{array}{c}36 \\
97.5(9.5)\end{array}$ & $\begin{array}{c}16 \\
89.7(17.0)\end{array}$ & 7.8 & 0.695 \\
\hline Subjects n & & 36 & 12 & & \\
\hline
\end{tabular}

Data are presented as mean (SE) unless otherwise stated and are from the patient population with total sleep time of at least $2 \mathrm{~h}$. Means are adjusted for baseline stage duration and baseline arterial oxygen tension. Latency to persistent sleep is the time in minutes to the first period of stage II sleep.

both comparisons), and there was a trend towards higher $\mathrm{Sa}, \mathrm{O}_{2}$ in those receiving tiotropium in the morning $(\mathrm{p}=0.14)$.

\section{Sleep quality}

Polysomnography data are presented in table 4 for those patients who had at least $2 \mathrm{~h}$ objective sleep on both baseline and end-of-study visits. Sleep disturbance was highly variable in these patients, but there were no significant differences in duration of sleep stages between the treatment groups. Subjective perception of sleep quality was assessed from the mean weekly score, calculated from the response to a specific question on sleep quality recorded in the patient's daily diary record. There was no significant effect of tiotropium on the patient perception of sleep quality score during any week of treatment. Furthermore, there were no differences in subjective daytime sleepiness between patients taking tiotropium and placebo, as assessed by Epworth scores. The Epworth score in the pooled tiotropium group was 5.7 versus 6.4 in the placebo group, both values being within the normal range.

\section{Spirometry}

Data for spirometry are given in table 5 and indicate significant improvements in pre- and post-sleep FEV1 $(0.19 \mathrm{~L}$ and $0.17 \mathrm{~L}$, respectively) for the pooled tiotropium group compared with placebo after 4 weeks of therapy. Similar improvements in FEV1 were seen when the entire, completed study population $(n=80)$ were analysed. Comparison of the changes from baseline in pre- and post-sleep FEV1 showed no significant difference between the tiotropium-AM and tiotropium-PM groups, but there were significant improvements in FEV1 in both tiotropium groups compared with placebo. Similar improvements with tiotropium compared with placebo were seen for pre- and post-sleep FVC $(0.31 \mathrm{~L}$ and $0.36 \mathrm{~L}$, respectively; table 5). The end-of-treatment FEV1

Table 5.-Effect of tiotropium (pooled AM and PM) versus placebo on pre- and post-sleep forced expiratory volume in one second (FEV1) and forced vital capacity (FVC)

\begin{tabular}{|c|c|c|c|c|c|}
\hline & Tiotropium & Placebo & Difference & p-value & $95 \% \mathrm{CI}$ \\
\hline $\begin{array}{l}\text { Pre-sleep FEV1 L } \\
\text { Patients n }\end{array}$ & $\begin{array}{c}0.91(0.03) \\
40\end{array}$ & $\begin{array}{c}0.72(0.05) \\
15\end{array}$ & 0.19 & 0.002 & $0.07-0.31$ \\
\hline $\begin{array}{l}\text { Post-sleep FEV1 L } \\
\text { Patients n }\end{array}$ & $\begin{array}{c}0.81(0.02) \\
38\end{array}$ & $\begin{array}{c}0.64(0.03) \\
16\end{array}$ & 0.17 & 0.0001 & $0.09-0.26$ \\
\hline $\begin{array}{l}\text { Pre-sleep FVC L } \\
\text { Patients n }\end{array}$ & $\begin{array}{c}2.18(0.07) \\
40\end{array}$ & $\begin{array}{c}1.87(0.12) \\
15\end{array}$ & 0.31 & 0.027 & $0.04-0.58$ \\
\hline $\begin{array}{l}\text { Post-sleep FVC L } \\
\text { Patients n }\end{array}$ & $\begin{array}{c}1.94(0.06) \\
38\end{array}$ & $\begin{array}{c}1.58(0.09) \\
16\end{array}$ & 0.36 & 0.001 & $0.15-0.57$ \\
\hline
\end{tabular}

Data are presented as mean (SE) from the patient population with total sleep time of at least $2 \mathrm{~h}(\mathrm{n}=56)$. Means are adjusted for end-point baseline and baseline arterial oxygen tension. Overall mean baseline FEV1: pre-sleep: 0.84 L; post-sleep: 0.76 L. Overall mean baseline FVC: pre-sleep: $2.03 \mathrm{~L}$; post-sleep: $1.79 \mathrm{~L}$. 
Table 6.-Correlation between mean oxygen saturation during rapid eye movement (REM) sleep and forced expiratory volume in one second (FEV1)

Pearson correlation coefficient p-value

\begin{tabular}{lll}
\hline Pre-sleep FEV1 & & \\
$\quad$ Baseline visit & 0.29 & 0.045 \\
$\quad$ End-of-treatment visit & 0.42 & 0.003 \\
Post-sleep FEV1 & & \\
$\quad$ Baseline visit & 0.28 & 0.064 \\
End-of-treatment visit & 0.36 & 0.013 \\
\hline
\end{tabular}

Data are from patient population with total sleep time of at least $2 \mathrm{~h}$ who also had REM sleep ( $n=47)$.

values correlated significantly with $\mathrm{Sa}, \mathrm{O}_{2}$ levels during REM sleep and with pre-sleep $\mathrm{Sa}_{\mathrm{a}} \mathrm{O}_{2}$ at the baseline visit (table 6).

\section{Discussion}

The present findings indicate that producing a sustained anticholinergic blockade by inhaling tiotropium improves $\mathrm{Sa}, \mathrm{O}_{2}$ during sleep in COPD patients regardless of whether the drug is taken in the morning or in the evening. These effects were accompanied by improvements in waking spirometry, but without significant change in subjective or objective sleep quality. The degree of improvement in sleep-related $\mathrm{Sa}, \mathrm{O}_{2}$ with tiotropium in the present report is similar to that previously reported with theophylline therapy [23], and the most significant increase in $\mathrm{Sa}_{2} \mathrm{O}_{2}$ was observed during REM sleep, which is clinically relevant since oxygen desaturation is greatest in COPD during this sleep stage [24].

Oxygen desaturation in COPD results primarily from a fall in minute ventilation and also from a worsening of preexisting ventilation-perfusion mismatching $[4,25]$. The present data favour a benefit of tiotropium in lessening hypoventilation in view of the observed improvements in spirometry, both night and morning. Further support for an improvement in lung function as an important mechanism of improvements in $\mathrm{Sa}_{\mathrm{a}} \mathrm{O}_{2}$, comes from the significant correlation between REM-related $\mathrm{Sa}, \mathrm{O}_{2}$ changes and FEV1. Oral theophylline therapy can lessen desaturation during sleep and has been shown to reduce the degree of air trapping in the lungs [23, 26] with consequent improvements in ventilation-to-perfusion relationships, which may further benefit arterial oxygenation. Tiotropium has also been demonstrated to reduce air trapping [27], which could have contributed to the improved $\mathrm{Sa}, \mathrm{O}_{2}$ levels seen with tiotropium in the present study. However, since the current authors did not measure static lung volume in the study-patient population, the authors are unable to comment directly on this possibility. It could be argued that adverse effects on sleep quality might lessen sleeprelated oxygen desaturation because of greater sleep fragmentation and reduced amounts of REM sleep. In the present study, sleep quality was not influenced by tiotropium, although a previous report has demonstrated some improvements in sleep quality with the short-acting anticholinergic, ipratropium [11].

The present authors found no significant differences in presleep $\mathrm{Sa}, \mathrm{O}_{2}$ between tiotropium- and placebo-treated patients, although there was a slight trend towards a higher pre-sleep $\mathrm{Sa}, \mathrm{O}_{2}$ during tiotropium-PM therapy compared with placebo. Thus, it is possible that the higher sleeping $\mathrm{Sa}, \mathrm{O}_{2}$ levels with tiotropium compared with placebo may reflect, in part, an improvement in awake $S \mathrm{a}, \mathrm{O}_{2}$ with tiotropium and, in part, a specific sleep-related effect, although the comparison of sleeping $\mathrm{Sa}_{\mathrm{a}} \mathrm{O}_{2}$ between tiotropium and placebo was adjusted for differences in baseline values. The current study findings are consistent with previous reports that have failed to show a relationship between correction of hypoxaemia and sleep quality in COPD $[9,10]$. Nonetheless, a reduction in sleeprelated oxygen desaturation may have important clinical benefits, since such desaturation has been reported to predispose to cardiac arrhythmias [2], elevation of pulmonary arterial pressure levels during sleep [28] and nocturnal death during exacerbations [3], and correction of nocturnal hypoxaemia has been reported to benefit some of these abnormalities [2, 28].

Sleep quality is generally poor in patients with COPD with diminished total sleep time, frequent arousals and diminished slow-wave and REM sleep stages [8-10]. This has been demonstrated in hypoxaemic patients and those with milder degrees of oxygen desaturation but severe airflow limitation [8]. Moreover the amount of stage REM varies from night to night, a factor which restricted the analysis of the present study's population, since saturation during REM sleep was the a priori primary outcome measure of the study. The present authors excluded patients who failed to achieve at least $120 \mathrm{~min}$ of objectively confirmed sleep from analysis of the primary outcome measure, which resulted in only 56 of the 80 completed patients being included in the primary data analysis. This restriction was made in advance of data analysis but did not bias the current findings since a post hoc analysis of $\mathrm{Sa}, \mathrm{O}_{2}$ during REM sleep in the full population of 80 completed patients showed similar improvements in REM $\mathrm{Sa}_{\mathrm{a}} \mathrm{O}_{2}$ during tiotropium therapy when compared to placebo.

Like other studies [29], the present authors found that the patients studied did not report daytime sleepiness, suggesting that their sleep was not disrupted enough to be perceived as nonrestorative. However, COPD patients report frequent night-time awakenings [30] in keeping with their increased amount of stages 0 and I sleep. The current authors did not see any significant improvement in these variables with tiotropium or in the subjective reports of sleep disruption. Any beneficial effect on sleep quality may require more prolonged treatment or a larger sample size given that there is a high degree of variability in sleep quality and as 1-yr studies of this drug reported improvement in health status having included measurements on the effect on subjective sleep quality [31]. It is notable, however, that there was no deterioration in subjective sleep quality as was seen in patients receiving high doses of long-acting inhaled $\beta$-agonists in one report [32]. A direct central nervous system effect of tiotropium on sleep quality is made less likely by the fact that studies in rats have shown that the drug does not penetrate the bloodbrain barrier to any relevant extent [33].

Since the duration of action of tiotropium allows a oncedaily dosing schedule, an important consideration related to potential sleep-related effects is the timing of the daily dose. The current authors found no significant difference in the effects on any of the study end-points between morning and evening administration. The effect of time of treatment with tiotropium $18 \mu \mathrm{g}$ once daily was investigated in an earlier study [34]. This study found that tiotropium produces sustained bronchodilation throughout $24 \mathrm{~h}$ and the bronchodilation is not affected by the timing of the daily dose. The randomisation of patients was evenly divided between the two $\mathrm{Pa}_{2} \mathrm{O}_{2}$ strata of $\mathrm{Pa}, \mathrm{O}_{2} \leqslant 8.65 \mathrm{kPa}(65 \mathrm{mmHg})$ and $\mathrm{Pa}, \mathrm{O}_{2}$ $8.78-9.98 \mathrm{kPa}(66-75 \mathrm{mmHg})$, and baseline characteristics were similar for the two strata. When the end-points in all completed patients were analysed, there were no effects of $\mathrm{Pa}, \mathrm{O}_{2}$ stratum on the outcome. Similarly, the effect of tiotropium on $\mathrm{Sa}_{2} \mathrm{O}_{2}$ during REM sleep in the patients with a total sleep time of at least $2 \mathrm{~h}$ was not dependent on the $\mathrm{Pa}, \mathrm{O}_{2}$ stratum at baseline. 
Although the effect of tiotropium on nocturnal oxygenation was relatively small, its presence confirms that the drug is active during established sleep and was achieved without any deterioration in subjective or objective sleep quality.

\begin{abstract}
Acknowledgements. The authors wish to thank all of the patients who took part in this trial. The authors also wish to thank all of the support staff at the investigational centres. The Tiotropium Sleep Study in COPD Investigators (listed by number of patients randomised) were: A. Williams, J. Rees, St. Thomas' Hospital, London, UK ( $n=15)$; R. Cayton, I. Chakravorty, Birmingham Heartlands Hospital, Birmingham, UK ( $n=13)$; J.A. van Noord, Atrium MC Heerlen, Heerlen, the Netherlands ( $\mathrm{n}=11)$; J.R. Stradling, Osler Chest Unit, Churchill Hospital, Oxford, UK (n=10); W. McNicholas, St. Vincent's University Hospital, Dublin, Ireland (n=9); P.M.A. Calverley, Aintree Chest Centre, Fazakerley Hospital, Liverpool, UK $(n=8)$; C. Hanning, M. Morgan, Leicester General Hospital, Leicester, UK (n=8); K. Patel, Western Infirmary, Glasgow, UK (n=6); J.E. Shneerson, Papworth Hospital, Cambridge, UK $(\mathrm{n}=6)$; S.A. Kilfeather, Institute for Cardiovascular and Respiratory Pharmaceutical Development, Clinical Research Unit, Business and Innovation Centre, Sunderland, UK $(n=4)$; J.R. Catterall, Bristol Royal Infirmary, Bristol, UK $(\mathrm{n}=3)$; and M. Elliott, St. James' Hospital, Leeds, UK $(n=2)$. NCE Brainwaves (Springfield, Lisburn, UK) assessed the polysomnography and $\mathrm{Sa}_{\mathrm{a}} \mathrm{O}_{2}$ data prior to database lock. Quintiles Laboratories (Quintiles Scotland Ltd, Research Avenue South, HeriotWatt University Research Park, Edinburgh, UK) conducted the analysis of the haematology, serum chemistry and urinalysis parameters.
\end{abstract}

\section{References}

1. McNicholas WT. Impact of sleep in COPD. Chest 2000; 117, Suppl. 2: 48-53s.

2. Tirlapur VG, Mir MA. Nocturnal hypoxemia and associated electrocardiographic changes in patients with chronic obstructive airways disease. $N$ Engl J Med 1982; 306: 125-30.

3. McNicholas WT, Fitzgerald MX. Nocturnal deaths among patients with chronic bronchitis and emphysema. BMJ 1984; 289: 878.

4. Caterall JR, Calverley PMA, McNee W, et al. Mechanism of transient nocturnal hypoxemia in hypoxic chronic bronchitis and emphysema. J Appl Physiol 1985; 59: 1698-1703.

5. Johnson MW, Remmers JE. Accessory muscle activity during sleep in chronic obstructive pulmonary disease. J Appl Physiol 1984; 57: 1011-1017.

6. Baust $\mathrm{W}$, Bohernt $\mathrm{B}$. The regulation of heart rate during sleep. Exp Brain Res 1969; 7: 169-180.

7. Goldstein RS, Ramcharan V, Bowes G, McNicholas WT, Bradley D, Phillipson EA. Effect of supplemental nocturnal oxygen on gas exchange in patients with severe obstructive lung disease. New Engl J Med 1984; 310: 425-429.

8. Calverley PM, Brezinova V, Douglas NJ, Catterall JR, Flenley DC. The effect of oxygenation on sleep quality in chronic bronchitis and emphysema. Am Rev Respir Dis 1982; 126: $206-210$.

9. Fleetham J, West P, Mezon B, Conway W, Roth T, Kryger M. Sleep, arousals, and oxygen desaturation in chronic obstructive pulmonary disease. The effect of oxygen therapy. Am Rev Respir Dis 1982; 126: 429-433.

10. Cormick W, Olson LG, Hensley MJ, Saunders NA. Nocturnal hypoxaemia and quality of sleep in patients with chronic obstructive lung disease. Thorax 1986; 41: 846-854.
11. Martin RJ, Bucher Bartelson BL, Smith P, et al. Effect of ipratropium bromide treatment on oxygen saturation and sleep quality in COPD. Chest 1999; 115: 1525-1532.

12. Maesen FP, Smeets JJ, Sledsens TJ, Wald FD, Cornelissen PJ. Tiotropium bromide, a new long-acting antimuscarinic bronchodilator: a pharmacodynamic study in patients with chronic obstructive pulmonary disease (COPD). Dutch Study Group. Eur Respir J 1995; 8: 1506-1513.

13. Littner MR, Ilowite JS, Tashkin DP, et al. Long-acting bronchodilation with once-daily dosing of tiotropium (Spiriva) in stable chronic obstructive pulmonary disease. Am J Respir Crit Care Med 2000; 161: 1136-1142.

14. Casaburi R, Mahler DA, Jones PW, et al. A long-term evaluation of once-daily inhaled tiotropium in chronic obstructive pulmonary disease. Eur Respir J 2002; 19: 217224.

15. American Thoracic Society. Standards for the diagnosis and care of patients with chronic obstructive pulmonary disease (COPD) and asthma. Am Rev Respir Dis 1987; 136: 225-244.

16. Quanjer PhH, Tammeling GJ, Cotes JE, Pedersen OF, Peslin $\mathrm{R}$, Yernault J-C. Lung volumes and forced ventilatory flows. Report working party standardisation of lung function tests European Community for Steel and Coal. Eur Respir J 1993; 6: Suppl. 16, 5-40.

17. American Thoracic Society. Indications and standards for cardiopulmonary sleep studies. Am Rev Respir Dis 1989; 139: $559-568$.

18. Rechtschaffen A, Kales A. A Manual of Standardized Terminology, Techniques and Scoring System for Sleep Stages of Human Subjects. Washington, US Government Printing Office, Public Health Service, 1968.

19. Johns MW. A new method for measuring daytime sleepiness: The Epworth sleepiness scale. Sleep 1991; 14: 540-545.

20. Johns MW. Daytime sleepiness, scoring and obstructive sleep apnoea. The Epworth sleepiness scale. Chest 1993; 103: 30-36.

21. Fleiss JL. The design analysis of clinical experiments. In: Analysis of Covariance and the Study of Change. New York, USA, John Wiley and Sons, 1986: pp. 186-219.

22. Senn S. Baseline and covariate information. In: Statistical Issues in Drug Development. Chichester, UK, John Wiley and Sons, 1997: pp. 95-109.

23. Mulloy E, McNicholas WT. Theophylline improves gas exchange during rest, exercise and sleep in severe chronic obstructive pulmonary disease. Am Rev Respir Dis 1993; 148: 1030-1036.

24. Douglas NJ, Calverley PMA, Leggett RJE, Brash HM, Flenley DC, Brezinova V. Transient hypoxaemia during sleep in chronic bronchitis and emphysema. Lancet 1979; 1: $1-4$.

25. Fletcher EC, Levin DC. Cardiopulmonary hemodynamics during sleep in subjects with chronic obstructive pulmonary disease. The effect of short- and long-term oxygen. Chest 1984; 85: 6-14.

26. Chrystyn H, Mulley BA, Peake MD. Dose response relation to oral theophylline in severe chronic obstructive airway disease. BMJ 1988; 297: 1506-1510.

27. Celli B, ZuWallack R, Wang S, Kesten S. Improvement in resting inspiratory capacity and hyperinflation with tiotropium in COPD patients with increased static lung volumes. Chest 2003; 124: 1743-1748.

28. Fletcher EC, Luckett RA, Miller T, et al. Pulmonary vascular hemodynamics in chronic lung disease patients with and without oxyhemoglobin desaturation during sleep. Chest 1989; 95: 757-766.

29. Collard P, Dury M, Delguste P, Aubert G, Rodenstein DO. Movement arousals and sleep-related disordered breathing in adults. Am J Respir Crit Care Med 1996; 154: 454 459.

30. Rennard SI, Decramer M, Calverley PMA, et al. The impact of COPD in North America and Europe: the patient's perspective of the Confronting COPD International survey. Eur Respir J 2002; 20: 1-7. 
31. Tashkin D, Kesten S. Long-term treatment benefits with tiotropium in COPD patients with and without short-term bronchodilator responses. Chest. 2003; 123: 1441-1449.

32. Jones PW, Bosh TK. Quality of life changes in COPD patients treated with salmeterol. Am J Respir Crit Care Med 1997; 155: 1283-1289.

33. Leusch A, Eichorn B, Müller G, Rominger K-L. Pharmacokinetics and tissue distribution of the anticholinergics tiotropium and ipratropium in the rat and dog. Biopharm. Drug Dispos 2001; 22: 199-212.

34. Calverley PMA, Lee A, Towse LJ, Witek TJ, Kesten S Effect of tiotropium bromide on circadian variation in airflow limitation in chronic obstructive pulmonary disease Thorax 2003; 58: 855-860. 